\title{
LA PROTECCIÓN DE LOS DERECHOS SUBJETIVOS DERIVADOS DE LAS FACETAS PRESTACIONAL Y DE DEFENSA DEL DERECHO A LA VIVIENDA DIGNA EN LA JURISPRUDENCIA DE TUTELA DE LA CORTE CONSTITUCIONAL
}

\author{
Mario Pedro Ríos Padilla** \\ Recibido: Enero 15 de 2015 \\ Aprobado: Mayo 10 de 2015
}

\begin{abstract}
RESUMEN
El presente artículo es un avance del proyecto de investigación titulado "El Derecho a la Vivienda Digna y las Acciones Constitucionales en Colombia: desarrollo en la jurisprudencia y doctrina constitucional (1991-2011)", y se defiende la tesis de que el derecho a la vivienda digna puede ser protegido judicialmente a través de la acción de tutela como derecho subjetivo. Con ese propósito se profundiza en los postulados expuestos por la doctrina y la jurisprudencia constitucional de la justiciabilidad de los derechos sociales. Se expondrán a su vez, aquellas decisiones en que la Corte Constitucional protegió el derecho a la vivienda digna, en la faceta de defensa frente a injerencias arbitrarias y la faceta prestacional de prohibición del retroceso de una obligación estatal definida.
\end{abstract}

Palabras Clave: Derechos sociales, vivienda digna, jurisprudencia, dignidad humana y respeto.

\footnotetext{
* Artículo avance del proyecto de investigación titulado "El Derecho a la Vivienda Digna y las Acciones Constitucionales en Colombia: Desarrollo en la Jurisprudencia y Doctrina Constitucional (1991-2011)" desarrollado por el Semillero de Investigación en Hermenéutica Jurídica -HERMES- adscrito al Grupo de Investigación en Hermenéutica Jurídica del Centro de Investigaciones Socio-Jurídicas "Laureano Gómez Serrano" de la Universidad Autónoma de Bucaramanga. En esta investigación participaron los egresados Carlos Arturo Duarte Martínez y Carlos Mario Frías Rubio. Participan en ella Andrés Felipe Parra Rivera y Leonardo Acosta Arengas.

** Estudiante de X Semestre de Derecho de la Universidad Autónoma de Bucaramanga. Miembro del Semillero de Investigación en Hermenéutica Jurídica -HERMES-. Por este ensayo su autor fue distinguido con una Mención Especial dentro de la $12^{\mathrm{a}}$ Edición del Concurso de Investigación Formativa "Octavio Arizmendi Posada"2013-2014 (Ensayo Jurídico).Correo electrónico: mrios8@unab.edu.co
} 


\title{
THE RIGHT TO DECENT HOUSING AND CONSTITUTIONAL ACTIONS IN COLOMBIA: DEVELOPMENT IN THE CASE-LAW OF THE CONSTITUTIONAL COURT (1991-2011)
}

\begin{abstract}
This paper is an update of the research, entitled "The right to decent housing and constitutional actions in Colombia: development in the case-law and constitutional doctrine (1991-2011)", and defends the thesis that the right to adequate housing can be judicially protected as a subjective right. For this purpose, it deepens in the principles set out by law and the constitutional doctrine of justiciability of social rights . It also covers decisions of the Constitutional Court that protected the right of decent housing as a defense against arbitrary interferences and as a prohibition of setting back a defined state obligation.
\end{abstract}

Key Words: Social Rights, decent housing, jurisprudence, human dignity and respect

\section{INTRODUCCIÓN}

La doctrina especializada en derechos sociales se lamenta de las consecuencias traídas por distinguir los derechos por generaciones y por pactos internacionales: una, de derechos civiles y políticos, y otra de derechos económicos, sociales y culturales. Esta distinción, tal como lo expone Pisarello (2007), en un principio se planteó como una herramienta didáctica con fines eminentemente expositivos que facilitaran su explicación académica, pero se tradujo en limitantes para la satisfacción de estos últimos.

En efecto, se entendió que los derechos de primera generación son de pura abstención, mientras que los derechos sociales son de prestación, cuya satisfacción está condicionada a la existencia de recursos públicos. Especialmente, en los sectores conservadores, lo anterior, sirvió para negar la justiciabilidad de los mismos por cuanto: "las garantías de los derechos sociales, son una cuestión de política económica a cargo del legislador y de la administración pública, por ello es un terreno ajeno y extraño a los jueces" (Pisarello, 2007, p. 80).

Inicialmente fue entendido el derecho a la vivienda digna, como uno de los derechos de prestación cuya garantía es competencia de los órganos 
con legitimación democrática, por ello, no era susceptible de ser protegido por medio de la acción de tutela puesto que la Corte Constitucional (Sentencia T 1318 de 2005), en una postura temprana, entendió que este derecho no se podía constituir como subjetivo.

Pero el Derecho (Bernal, 2008, p. 195), como la cultura y principalmente todo lo que rodea la vida del ser humano no deja de ser inmune al surgimiento y el declive de modas y tendencias que permiten el cambio y que se refleja en la evolución del pensamiento para crear nuevas teorías y asegurar la satisfacción de los derechos del hombre.

Sobre esta base, la doctrina planteó una nueva tesis bajo la cual, en un Estado constitucional ambos tipos de derechos son fundamentales, condición que no se merma por la falta de garantías legislativas ni judiciales y que de no existir, la jurisprudencia, principalmente, debe establecer o adecuar mecanismos que efectivicen los derechos sociales. De no hacerlo, no se negaría el carácter justiciable de los derechos sociales, sino su misma condición de derecho, pues "lo que califica la existencia de un derecho social como derecho pleno, es la existencia de algún poder jurídico para actuar por parte del titular del derecho, en caso del incumplimiento de una prestación debida" (Abramovich \& Courtis, 2000,pp. 37-38).

De la mano de la anterior postura, un sector vanguardista de la doctrina ha puesto de manifiesto que todos los derechos fundamentales, civiles y sociales, demandan un gasto de recursos públicos y tienen facetas de prestación y defensa.

Lo anterior, ha sido recogido por la jurisprudencia constitucional colombiana. Así, en la SU 062 de 2010 la Corte Constitucional señaló que: "Los derechos civiles, políticos, económicos, sociales o culturales en cuanto a que son fundamentales tienen distintas facetas prestacionales, que incluso el Estado, tiene frente a los derechos sociales deberes negativos".

El derecho a la vivienda digna se definió como "aquel dirigido a suplir la necesidad humana de disponer de un sitio de vivienda, sea propio o ajeno, que revista las características para poder realizar de manera digna, el proyecto de vida" (Corte Constitucional, Sentencia T 958 de 2001). Sobre esta base, La Corte Constitucional, también ha desarrollado la acción de tutela como mecanismo judicial para su protección, tanto en su esfera de prestación como de defensa. 
Esto último, ha sido el resultado del reconocimiento de una insuficiencia legal de protección del derecho a la vivienda digna, frente a la creciente cantidad de casos fácticos, en los cuales se aprecia el desinterés estatal en el cumplimiento de la obligación de garantizarlo por medio de acciones y políticas efectivas.

Progresivamente, la Corte referida desarrolló una tesis de justiciabilidad del derecho a la vivienda digna. En principio (Corte Constitucional, sentencia T 585 de 2008), sostuvo que era posible su protección como derecho de prestación mediante una tutelabilidad indirecta, bajo la cual para ser protegido el derecho a la vivienda digna por vía de acción de tutela, se debía demostrar la conexidad con la vulneración de un derecho fundamental subjetivo clásico, civil o político, como lo es, el derecho a la vida, o bien, la afectación del mínimo vital en personas que se encontraran en situación de debilidad manifiesta.

Posteriormente, la Corte Constitucional adoptó una nueva postura (sentencias T 1318 de 2005, T 761 de 2011, y T 1318 de 2005) acorde con la concreción de los postulados esgrimidos específicamente por un sector de la doctrina, y reconoció el derecho a la vivienda digna como derecho subjetivo tanto en su faceta prestacional, como de defensa y por ende, susceptible de ser protegido de manera directa por medio de la acción de tutela, si procesalmente se acredita que hubo un retroceso de una obligación estatal definida o una injerencia arbitraria por parte del Estado, respectivamente.

Superar la indeterminación de las condiciones de exigibilidad del derecho a la vivienda digna, y establecer los mecanismos para su efectiva protección judicial, son los principales propósitos del proyecto titulado "El Derecho a la Vivienda Digna y las Acciones Constitucionales en Colombia: Desarrollo en la Jurisprudencia y Doctrina Constitucional (1991-2013)", adelantado dentro del Semillero de Investigación en Hermenéutica Jurídica-HERMES-.

El presente escrito es resultado de una labor exploratoria de la jurisprudencia de tutela de la Corte Constitucional y busca reconocer las condiciones bajo las cuales el derecho social a la vivienda digna es objeto de tutelabilidad directa, por cuanto adquiere la estructura de derecho subjetivo de una doble manera: en la aplicación de las facetas de defensa frente a actuaciones arbitrarias, y en su faceta de prestación prohibiendo el retroceso de una obligación estatal definida en un programa estatal. 
Con el fin de organizar esta exposición, siguiendo cierto orden sistemático se proyectará que la conclusión es producto de: 1) exponer los fundamentos del reconocimiento de la faceta de defensa y de prestación del derecho a la vivienda digna consagrados por la doctrina, la jurisprudencia de la Corte Constitucional, y los instrumentos internacionales; 2) definir la naturaleza jurídica del derecho a la vivienda digna, a partir del análisis de su estructura y núcleo esencial como derecho subjetivo, en su faceta de defensa y prestacional; 4) Demostrar la aplicación de la tesis de la tutelabilidad directa del derecho a la vivienda digna, por medio de las sentencias de tutela revisadas por la Corte Constitucional, aquellas que establezcan la faceta de defensa y de prestación; para 5) finalizar con unas conclusiones.

\section{FUNDAMENTOS DEL RECONOCIMIENTO DE LA FACETA DE DEFENSA DEL DERECHO A LA VIVIENDA DIGNA}

\subsection{Doctrina y Jurisprudencia de la Corte Constitucional}

La posición clásica de la doctrina discrimina entre derechos civiles y políticos, con respecto de los derechos sociales, bien sea por su estructura o porque los primeros ostentan la condición de ser derechos subjetivos y los segundos se conciben como derechos de condición programática, esto es, que acarrean obligaciones estatales y su satisfacción depende necesariamente, de los recursos del erario público.

Sostener esta tesis implica que los derechos civiles y políticos generan obligaciones negativas, que se transforman en una obligación de no hacer por parte del Estado: no sancionar a una persona sin antes haber respetado el derecho al debido proceso, no aplicar la pena de muerte. Por el contrario, la estructura de los derechos sociales se caracteriza por exigir al Estado la realización de obligaciones positivas: garantizar el acceso a los servicios públicos, promover planes de vivienda de interés social, etc. En el primer caso: "Bastaría con limitar la actividad del Estado, prohibiéndole su actuación en algunas áreas; en el segundo, el Estado debería necesariamente, erogar recursos para llevar a cabo las prestaciones positivas que se le exigen" (Abramovich \& Courtis, 2000, p. 21).

Los derechos a prestaciones en sentido estricto: "son derechos del individuo frente al Estado, algo que si el individuo poseyera medios financieros suficientes y si encontrase en el mercado una oferta 
suficiente, podría obtenerlo también de particulares" (Alexy, 1993, p. 482). Por ello, cuando se habla de derechos sociales fundamentales en el caso de la vivienda digna, se relaciona el mismo con un derecho a prestación en sentido estricto.

Pero el debate surge cuando se exponen otras posturas novedosas, las cuales consideran que los derechos sociales tienen una doble connotación: como derecho subjetivo, y como derecho prestacional, de índole patrimonial. Para afirmar este punto de vista, el maestro Gómez (2008) plantea que:

El ciudadano puede detentar frente al Estado, derechos para imponerle acciones negativas o de defensa, a fin de que no afecte sus propiedades, y a que no elimine ciertas posiciones jurídicas; Pero también puede tener, derechos a acciones positivas, unas cuyo objeto es una acción fáctica o de "prestación"; otras, cuyo objeto es una acción normativa (p. 105).

Teniendo en cuenta lo anteriormente expuesto, la tensión del debate actual sobre los derechos sociales, releva a un segundo plano la pugna entre los derechos civiles y políticos, por un lado, y los derechos sociales, por otro.

Luigi Ferrajoli (2004) ha postulado la siguiente definición de derechos fundamentales que le da cabida a todas las generaciones:

Son todos aquellos derechos subjetivos que corresponden universalmente a todos los seres humanos en cuanto dotados del status de personas, de ciudadanos o personas con capacidad de obrar; entendiendo por derecho subjetivo cualquier expectativa positiva (de prestaciones) o negativa (de no sufrir lesiones) adscrita a un sujeto por una norma jurídica; y por status, la condición de un sujeto, prevista asimismo por una norma jurídica positiva, como presupuesto de su idoneidad para ser titular de situaciones jurídicas y/o autor de los actos que son ejercicio de estas (p. 37).

De la misma manera, la Corte Constitucional en sentencia T 235 de 2011, precisó que: "los derechos fundamentales poseen una estructura compleja o una multiplicidad de facetas, por lo que su satisfacción 
acarrea el cumplimiento de un haz de obligaciones tanto positivas como negativas para el Estado". Sobre esta base, "atribuir la cualidad de prestacional a un derecho, es un error categorial, pues esa característica se predica de algunas de sus facetas y no del derecho considerado como un todo" (Corte Constitucional, sentencia T 760 de 2008).

Sobre esta base (Roca \& González, 2004, p. 1306), el derecho a la vivienda digna como derecho de defensa, protege a quien ya disfruta de una vivienda digna frente a actuaciones realizadas bien sea por parte de la Administración, como de particulares consistentes en la privación de la misma o en la limitación de su disfrute, salvo que dichas intervenciones se encuentren justificadas.

Simultáneo a la faceta de defensa, se encuentra, la prestacional. En este contexto, "el Estado no suministra el bien jurídico en cuanto tal, sino que ayuda, mediante típicas técnicas de fomento, a quienes no pueden obtenerlo por sus medios, a fin de que estos puedan completar las cantidades necesarias para su financiación" (Roca \& González, 2012, pp. 1308). Por otro lado, se establece que en casos excepcionales, el Estado debe otorgar la vivienda, sin financiaciones parciales.

Según Abramovich \& Courtis (2000, pp. 129-131), el primer problema que enfrenta el concebir los derechos sociales como fundamentales, bajo las facetas de defensa y prestacional, en contra del menoscabo sufrido por acciones u omisiones de la administración pública, vendría a ser la carencia de mecanismos procesales adecuados para garantizar su exigibilidad, ya que las acciones judiciales tipificadas por el ordenamiento jurídico han sido pensadas para la protección de los derechos civiles y políticos clásicos; de igual manera, pese a la existencia de normas de jerarquía constitucional que consagran estos derechos, concepciones conservadoras, acerca del papel institucional del poder judicial y de la separación de poderes, suelen provocar una escasa práctica de exigencia judicial de estos derechos, y un menosprecio de las normas que los instituyen.

A cuenta de la problemática planteada, se describirán las estrategias que se han planteado para garantizar la tutela judicial de los derechos sociales, siendo la primera, la exigibilidad indirecta, y la segunda, la exigibilidad directa.

La exigibilidad indirecta de un derecho social, "aprovecha las posibilidades de justiciabilidad y los mecanismos de tutela que brindan 
otros derechos, de modo de permitir, por esa vía, el amparo del derecho social en cuestión" (Abramovich \& Courtis, 2000, p. 168).

La exigibilidad directa, como lo establecen Abramovich \& Courtis (2000), ocurre en:

Los casos en los que la violación de la obligación estatal resulta clara, y la conducta debida por el Estado para reparar la violación pueda señalarse sin dificultad; las acciones judiciales deben estar dirigidas a obtener del Estado la realización de la conducta debida para reparar la violación del derecho, del mismo modo que frente a la violación de cualquier otro derecho civil o político ( $\mathrm{p}$. 133).

Como corolario de lo anterior, cuando le sea solicitada al juez de tutela la protección del derecho a la vivienda digna, dicha autoridad no podrá negar la procedibilidad del amparo haciendo referencia al carácter no fundamental del derecho. De igual manera, tampoco necesitará recurrir al criterio de la conexidad. Deberá "identificar en atención a las circunstancias del caso concreto, si la pretensión debatida en sede de tutela hace parte de la faceta de defensa o de prestación del derecho" (Corte Constitucional, Sentencia T 585 de 2008).

Por último, se pone en contexto la relación entre la teoría de la exigibilidad directa de los derechos sociales, con la cláusula de prohibición de retroceso social planteada por Bernal (2008), la cual instituye que:

Al legislador le está vedado desmontar aquellas medidas que ha adoptado para desarrollar los derechos sociales cuando estos adquieren un determinado grado de realización. Los individuos beneficiarios de las prestaciones sociales tienen derecho a seguir disfrutando de ellas, y por tanto pueden instaurar pretensiones de inconstitucionalidad en contra de leyes que intenten desarticularlas (p. 319).

Esta característica es importante y como se verá más adelante es uno de los argumentos que utiliza la Corte para proteger derechos subjetivos derivados del desarrollo de la vivienda digna, en su faceta prestacional. 


\subsection{Instrumentos internacionales}

Un aspecto importante sobre el Derecho, son precisamente las regulaciones que por tener un contenido sobre temas especialmente sensibles a la humanidad, convergen en normas que vinculan a varios estados del mundo.

En primer lugar, es necesario referirse al Pacto Internacional de Derechos Económicos, Sociales y Culturales (1966), el cual establece que:

Los Estados Partes en el presente Pacto, reconocen el derecho de toda persona a un nivel de vida adecuado para sí y su familia, incluso alimentación, vestido y vivienda adecuados, y a una mejora continua de las condiciones de existencia. Los Estados Partes tomarán medidas apropiadas para asegurar la efectividad de este derecho, reconociendo a este efecto la importancia esencial de la cooperación internacional fundada en el libre consentimiento (Artículo 11).

Para reforzar la protección fundamental que debe tener el derecho social a la vivienda digna, resulta obligada la referencia a la Observación General $n^{\circ} 4$ (en adelante OG) del Comité de Derechos Económicos, Sociales y Culturales de las Naciones ${ }^{1}$, aplicable a la normatividad colombiana en virtud del artículo 93 de la Constitución Política y conforme a los artículos 16 y 17 del Pacto Internacional de Derechos Económicos, Sociales y Culturales.

El contenido desarrollado dentro de la OG (1991) trata sobre el derecho a una vivienda adecuada, interpretándolo principalmente como el derecho a vivir en un sitio que brinde seguridad, paz y tranquilidad. De conformidad con lo anterior, se identifican en la $\mathrm{OG}$, siete aspectos que pueden considerarse componentes o aspectos presentes en cualquier contexto: Seguridad jurídica en la tenencia, disponibilidad de servicios, materiales, facilidades e infraestructuras, gastos soportables (accesibilidad económica), habitabilidad, asequibilidad (accesibilidad física), lugar adecuado y adecuación cultural.

La referencia a la seguridad jurídica pone de presente, que debe protegerse hasta la más precaria forma de tenencia de una vivienda, lo

1 Es el órgano encargado de la interpretación y la vigilancia del cumplimiento del Pacto Internacional de Derechos Económicos, Sociales y Culturales. 
que implica que una vez se adquiere una de ellas "adquiere la configuración de un derecho de defensa frente a injerencias arbitrarias de las autoridades estatales o de particulares" (Corte Constitucional, Sentencia T 1318 de 2005).

Respecto a la Observación General $N^{\circ} 4$, la Corte Constitucional ha destacado su importancia ya que es un "referente interpretativo" (Sentencia T 530 de 2011), que "establece criterios para determinar el contenido del artículo 51 constitucional" (Sentencia T 495 de 2010). También la doctrina ha señalado que "las Observaciones generales del comité de Derechos Económicos, Sociales y Culturales constituyen un buen ejemplo de esta tarea de especificación del contenido de los derechos establecidos en el PI-DESC" (Abramovich \& Courtis, 2000, p. 123).

\section{NATURALEZA JURÍDICA DEL DERECHO A LA VIVIENDA DIGNA}

El derecho a la vivienda digna se encuentra consagrado en el artículo 51 de la Constitución política de Colombia, y el mismo dispone que:

Todos los colombianos tienen derecho a vivienda digna. El Estado fijará las condiciones necesarias para hacer efectivo este derecho y promoverá planes de vivienda de interés social, sistemas adecuados de financiación a largo plazo y formas asociativas de ejecución de estos programas de vivienda.

La Corte Constitucional de Colombia (Sentencia T 958 de 2001), es la llamada a exponer la correcta interpretación de cualquier norma constitucional, y reconoció que el artículo 51 de la misma, tiene una configuración positiva compleja pues contempla diversas hipótesis que exigen tratamientos jurídicos distintos.

Así, estableció que para interpretar el artículo 51 constitucional es necesario dividirlo en dos partes. Procedió entonces, a abordar el primer inciso (Corte Constitucional, Sentencia T 1318 de 2005), del cual reconoció que se caracteriza por contener una textura abierta e indeterminada al disponer, que el derecho a la vivienda digna es para todos los colombianos. Pero, a pesar de la estructura ya establecida, la Corte estableció que en aquellos casos en los cuales las autoridades estatales han incumplido sus obligaciones de respeto y garantía, y han 
afectado el derecho a la vivienda digna, este mismo adquiere la configuración de un derecho de defensa frente a injerencias arbitrarias de las autoridades estatales o de particulares.

Ahora bien, respecto de los contenidos normativos restantes del artículo 51 constitucional, la Corte (Sentencia T 1318 de 2005) estableció que ellos consagran el carácter de derecho prestacional y progresivo del derecho a la vivienda digna, pero que en su desarrollo pueden surgir derechos subjetivos. Esto significa que:

Estarían en principio sujetos a la definición de políticas públicas estatales, sin embargo, una vez definidas tales políticas públicas por los órganos con competencia en esta esfera, trátese del poder legislativo o de la administración en sus distintos niveles territoriales, se pueden constituir derechos subjetivos de carácter iusfundamental susceptibles de protección por intermedio de la acción de tutela.

\subsection{Estructura del derecho social a la vivienda como derecho fundamental}

Desde el punto de vista de la estructura, el catedrático Gómez (2008, pp. 123-124) dispuso que un derecho fundamental se caracteriza por tener tres elementos: el titular, el destinatario, y el objeto, los cuales están, en relación entre sí. Así, el titular es el sujeto portador del derecho, que puede ser una persona natural, la cual ejercita el derecho fundamental. El destinatario, es el sujeto vinculado al respeto del derecho fundamental, por ende, es quien debe una prestación o abstención. Por último, el objeto se entiende como las acciones positivas u omisiones que debe realizar el destinatario, para evitar la perturbación del derecho.

A continuación se presenta la estructura del derecho a la vivienda digna desde sus dos facetas de comportamiento establecidas por la Corte Constitucional con base en la doctrina, y derivadas del artículo 51 constitucional, que se estudian en el presente escrito.

\subsubsection{La faceta de defensa frente a injerencias arbitrarias}

Se propone la siguiente definición: Es la acción u omisión unilateral, llevada a cabo por una entidad estatal, que afecta o amenaza el disfrute 
pacífico de la vivienda de un particular, y sobre esta base permite la protección del derecho a la vivienda digna vulnerado, de manera directa, por medio de la acción de tutela.

El sujeto llamado a ejercer la protección del derecho a la vivienda digna en la faceta de defensa, es una persona natural caracterizada, en primer lugar, por estar impedido de gozar del disfrute pacífico de su vivienda, producto, de una acción u omisión realizada por una entidad estatal; en segundo lugar, debe, habitar la vivienda, sin que sea importante si es su propietario o no, bien sea de manera previa o durante la injerencia arbitraria. En estas condiciones, esa persona puede solicitar la protección judicial de su derecho fundamental a una vivienda digna, por medio de la acción de tutela.

A pesar de que la Corte Constitucional establece la faceta de defensa frente a injerencias arbitrarias de las autoridades estatales o de particulares; el presente ensayo jurídico se centra únicamente en las relaciones de los particulares frente al Estado, siendo este último, el destinatario obligado a cumplir el objeto de la protección.

Por último, el objeto que condiciona la actuación del Estado está encaminado a abstenerse de seguir realizando las injerencias tomando las medidas necesarias para restituir el disfrute pacífico de los particulares propietarios de la vivienda, así como de sus familiares.

\subsubsection{La faceta prestacional de prohibición del retroceso de una} obligación estatal definida: Es la faceta del derecho a la vivienda digna bajo la cual un particular, haciendo uso de la acción de tutela, exige el cumplimiento de las políticas públicas definidas por una entidad estatal, y reconocidas positivamente en su favor, para acceder a una vivienda, toda vez, que dicha autoridad cambió de manera intempestiva, las condiciones pactadas inicialmente, negando al particular el acceso al programa público, sin la debida argumentación que justifique esa decisión.

Esta tesis, se basa en el criterio de la transmutación del derecho a la vivienda digna establecida por la Corte Constitucional en Sentencia T 585 de 2008, siendo:

Aquella situación en la que, una vez definidas las políticas públicas de distribución de los recursos, los criterios de asignación, y los requisitos y procedimientos para el 
reconocimiento de derechos económicos, sociales y culturales, se constituyen derechos subjetivos que pueden ser exigidos en sede de tutela, cuando se constate en los casos concretos que los mecanismos para la protección de estos derechos no son idóneos, o que con el ejercicio de la acción de amparo se busca evitar la consumación de un perjuicio irremediable.

El sujeto que puede pedir la protección del derecho a la vivienda digna, en la faceta prestacional de prohibición de medidas regresivas de una obligación estatal definida, es una persona natural que si bien no es propietario de una vivienda, sí es el titular de una política pública definida y reconocida de manera positiva, mediante un documento público, bien sea una promesa de contrato, pero a la cual no puede acceder por el cambio intempestivo de las condiciones inicialmente pactadas por la administración.

El Estado es el destinatario obligado, por cuanto suscribió una obligación prestacional de desarrollar un programa a partir de una política pública definida para que unos particulares puedan acceder a una vivienda, y posteriormente, cambió las condiciones pactadas, las cuales afectaron desfavorablemente a aquellos quienes ya se les había establecido decisiones de satisfacción.

Es necesario evidenciar que el Estado siempre debe argumentar las razones de esa decisión regresiva, y dado el caso en el cual aporte un argumento consistente, puede desvirtuar esa transgresión del derecho a la vivienda digna.

El objeto, que condiciona la actuación por parte de la entidad estatal, se refiere indiscutiblemente al cumplimiento de las condiciones originalmente pactadas con el particular, titular de la política pública definida.

\subsection{Núcleo esencial}

Doctrinalmente, Gómez (2008, pp. 109-115) enuncia que, establecer el contenido esencial de un derecho fundamental ha sido un tema polémico por la doble connotación entre la esfera externa (derecho subjetivo), y la esfera interna (contenido esencial o mínimo). Desde este punto de vista, el límite entre lo externo y lo interno lo debe determinar el tribunal constitucional. 
La Corte Constitucional acoge la teoría objetiva, la cual determina el contenido esencial: "como aquel mínimo que impide que el derecho sea reducido de tal forma, que pierda toda importancia para el individuo, para la mayor parte de ellos, o para la sociedad" (Gómez, 2008, p. 115).

La idea adoptada consiste en que es necesario establecer el contenido esencial del derecho a la vivienda digna en las dos facetas analizadas, porque de lo contrario, en palabras de Pisarello (2003, p. 108), el derecho quedaría desnaturalizado e impracticable.

Sobre la base anteriormente planteada, el contenido esencial del derecho a la vivienda digna establecido por la Corte Constitucional, se refiere específicamente al respeto por la dignidad humana así como, de las obligaciones estatales definidas.

En primer lugar, la Corte Constitucional establece que respeto es la "obligación radicada en cabeza del Estado y los particulares, de abstenerse de injerir sin justificación suficiente, directa o indirectamente, en el disfrute del derecho a la vivienda digna" (Sentencia T 761 de 2011).

La dignidad humana como valor fundante y principio rector de los derechos constitucionales, y principalmente del actuar del Estado colombiano, así como de los particulares, en los términos de la Corte Constitucional, "no se aplica exclusivamente para la adquisición de vivienda, sino acorde con el valor de la persona humana, para tener un proyecto de vida plena, libre y auto realizada" (Sentencia T 308 de 1993).

Por otro lado, para la Corte Constitucional (sentencia T 309 de 1995) el respeto de los derechos subjetivos previstos en el marco de desarrollos legales, como lo es el establecimiento de políticas públicas definidas, se refiere a que:

Las obligaciones sociales del Estado contempladas en el artículo 2 de la Constitución Política de Colombia, no pueden supeditarse a la nimiedad del formalismo, ni postergarse indefinidamente, por esa misma causa, la cristalización de objetivos que inciden en los derechos fundamentales.

Es claro, primero los derechos que la ley. 


\section{LA TUTELABILIDAD DIRECTA DE LA FACETA SUBJETIVA DEL DERECHO A LA VIVIENDA DIGNA EN LA JURISPRUDENCIA DE LA CORTE CONSTITUCIONAL}

A continuación se presentan los análisis de una recopilación de sentencias de tutela de la Corte Constitucional, para presentar los casos fácticos en donde ella desarrolló las facetas de defensa frente a injerencias arbitrarias del Estado, así como la faceta prestacional de prohibición del retroceso de una obligación estatal definida.

Para la recopilación de sentencias se utilizó la técnica de la ingeniería reversa y la de la telaraña citacional o nicho jurisprudencial, propuesta por Diego López Medina (2000). Se advierte que no fue posible elaborar líneas jurisprudenciales debido a que no se contaba con un número plural de sentencias que versaran sobre un mismo caso fáctico, sobre el cual elaborarla.

Adelante, se expondrán cinco sentencias de la Corte Constitucional, que se dividen en dos grupos según su relación con el surgimiento de la vivienda digna como derecho subjetivo, en su faceta prestacional y de defensa:

\subsection{El derecho a la vivienda digna en garantía de prohibición del retroceso de una obligación estatal definida}

En los tres casos siguientes se está frente a medidas regresivas de decisiones estatales, que le impidieron adquirir una vivienda digna a una persona natural, que si bien no es propietaria de ella, sí es el titular de una política pública definida para obtenerla.

La primera sentencia es la T 761 de 2011, en la cual se estudian dos casos fácticos, que versan sobre el mismo asunto, y por lo tanto su decisión es similar.

En el primero, debe resolver la Corte si se vulnera el derecho a la vivienda digna, de una persona que en un principio se le autorizó recibir un subsidio de vivienda familiar, por parte de una entidad estatal (caja de compensación familiar), pero que en un segundo momento, la misma le negó el subsidio, por cuanto la obra de interés social fue terminada en una fecha posterior a la planeada, cuando ya había vencido el plazo para utilizar la ayuda estatal ya referida. 
En el segundo caso, la Corte resuelve si se viola el derecho a la vivienda digna de una persona, que a pesar de haber alcanzado un subsidio familiar para acceder a una vivienda, quedó sin la posibilidad de obtenerla, por cuanto del proyecto de vivienda de interés social en el cual estaba postulado, solo fue construida una primera etapa por falta de presupuesto, en la cual no estaba el inmueble prometido del accionante, y en razón a la misma, le negaron el subsidio de vivienda logrado, y lo sancionaron impidiéndole postularse en el otro programa de vivienda de interés social por 10 años. Para la Corte en ambos casos: "Las acciones de tutela se interpusieron para exigir el cumplimiento por parte de los entes demandados de una obligación de respeto". Así mismo, ubica las pretensiones de los actores, en la faceta prestacional del derecho a la vivienda digna, por cuanto "la autorización de desembolso de subsidios familiares de vivienda y la orden de entrega de viviendas de interés social, hacen parte de las políticas públicas para garantizar el acceso de las personas a una vivienda digna".

Respecto del primer caso fáctico, la Corte falla bajo las siguientes consideraciones: Si bien la Caja de Compensación Familiar, actuó dando cumplimiento de los requisitos legales (artículo 59 del Decreto 2190 de 2009, norma que reglamenta los subsidios familiares de vivienda en zonas urbanas) indica que en aquellos eventos en los que los administrados hayan creado situaciones jurídicas con fundamento en actuaciones previas de las autoridades públicas, estas deben ser reconocidas por dichas autoridades, así no correspondan con los lineamientos y formalidades previamente establecidos.

Es decir, que el cumplimiento tardío de las obras de construcción de las viviendas del programa adelantado, no era imputable a la acción u omisión del particular beneficiado, por lo que no podía derivársele para ella una consecuencia gravosa.

En este caso, la actuación de la Caja de Compensación Familiar generó una expectativa legítima de la tutelante, la cual consistió en que: la adquisición de su vivienda, iba a ser cubierta parcialmente con los recursos del subsidio familiar de vivienda. En consecuencia, la corte, ordena a la entidad legalizar y desembolsar el subsidio prometido. Respecto del segundo caso, la Corte concluye que:

Existe una vulneración evidente del derecho a la vivienda digna ocasionada en la negligencia de las entidades municipales accionadas de cumplir con sus obligaciones 
constitucionales y legales. Este derecho fundamental debe ser protegido por medio de la acción de tutela, teniendo en cuenta que las entidades accionadas adelantaron gestiones que generaron derechos particulares en cabeza del actor.

Por consiguiente, se ordenó la postulación nuevamente del actor para la asignación de una solución de vivienda ofrecida por esa entidad, y que la misma, le sea asignada respetando el orden de adjudicación que tenía desde su primera postulación, para adquirir una vivienda en el proyecto Ciudadela el Progreso, previo cumplimiento por parte del tutelante de los requisitos que para su acceso se establezcan.

En esta Sentencia T 761 de 2011, la Corte Constitucional reitera la posición que había definido en la Sentencia T 585 de 2008, respecto de la faceta prestacional del derecho a la vivienda digna.

Por ello, la segunda sentencia a exponer es la T 585 de 2008. En esta, le corresponde a la Corte Constitucional resolver si viola el derecho a la vivienda digna, una entidad estatal que excluye a una familia del programa de reasentamiento de un grupo de viviendas declaradas en zonas de alto riesgo, porque el accionante adquirió la vivienda mediante promesa de compraventa y empezó a habitarla luego de que se emitiera el concepto técnico que declaró el estado de alto riesgo en el sector. En este caso, la Corte establece que:

Respecto de aquellas prestaciones que han sido reconocidas positivamente, por vía legal o reglamentaria, a favor de los individuos, de forma tal que pueden ser definidas como derechos subjetivos, es admitido el carácter iusfundamental de la vivienda digna, con fundamento en el criterio de la transmutación.

A partir de lo anterior, la Corte Constitucional (Sentencia T 585 de 2008) resalta que:

El elemento que se traduce en la necesaria definición de las políticas públicas que, en atención a la disponibilidad de recursos, establezcan las condiciones en las que se garantizará su disfrute, es un argumento que apunta en realidad a describir la forma como este derecho puede hacerse efectivo en la práctica y no a desconocer la 
necesaria protección que el mismo merece, en cuanto derecho fundamental, aspecto que deviene indiscutible una vez establecida su imperiosa protección de cara al respeto de la dignidad humana.

Se tiene entonces, que la Corte consideró que no estaba justificada la exclusión de la familia del demandante, del programa de reasentamiento bajo la consideración de que él había ocupado la vivienda después de que se había declarado la zona como de alto riesgo, pues al fin y al cabo cuando se produjo el desalojo de la viviendas ubicadas en esa zona, él y su familia la estaban habitando, sufriendo un menoscabo directo a su derecho a la vivienda digna del cual en el caso en particular eran titulares legítimos.

También la Corte resalta que aunque el demandante y su familia empezaron a habitar la vivienda en virtud de un contrato de promesa de compraventa, que no transmite la propiedad de la misma, ello en ningún modo puede traducirse en el fundamento de una afectación al derecho a la vivienda digna, en especial porque "las normas en la materia prevén que incluso si este es considerado un mero poseedor del predio tendrá el derecho a ser cobijado por el programa de reasentamientos". Se ve entonces, que puede protegerse hasta la relación más precaria entre una persona y el inmueble de vivienda. Como consecuencia de lo anterior, la Corte ordena a la entidad demandada:

Incluir al accionante y a su grupo familiar en un programa de reasentamientos con fundamento en el cual se garantice el acceso de estas personas a todas aquellas prestaciones a las que tienen derecho los habitantes de las zonas declaradas de alto riesgo no mitigable en aplicación de las normas en la materia.

En conclusión, la Corte pone énfasis no en el origen de la situación de amenaza al derecho a la vivienda digna, sino en las posibilidades de solución.

La tercera sentencia que se procede a exponer, es la T 1318 de 2005, en la cual se debate si se viola el derecho a la vivienda digna, cuando intempestivamente la administración pública cambia la obligación contractual originaria y disminuye su aporte de capital a la financiación de un programa de vivienda de interés social, obligando a los particulares, que ya se habían reconocido como beneficiarios, deban 
sufragar una mayor erogación de sus recursos para acceder a la vivienda, los cuales no tienen. Señala la Corte, que en este caso:

Debido precisamente a la definición de una política pública por el Municipio de Palmira, consistente fijar subsidios municipales para adquirir vivienda de interés social en la Urbanización El Sembrador el derecho a la vivienda digna adquirió el carácter de derecho subjetivo, el cual puede ser protegido por medio de la acción de tutela. En efecto, en este caso no se debate el alcance o la naturaleza prestacional del derecho ni los deberes abstractos de las autoridades estatales para su concreción, sino de un derecho subjetivo de acceso a una subvención estatal plenamente definida en virtud de decisiones adoptadas por los poderes públicos competentes en la materia.

La Corte Constitucional analiza la medida regresiva de la administración municipal, y destaca que de la misma se desprende una presunción de inconstitucionalidad, que prohíbe ese comportamiento, pero no obsta que se pueda desvirtuar a raíz de una justificación oportuna y concreta por parte de aquella autoridad que la adoptó.

Se encuentra entonces, que las dos principales razones expuestas por la autoridad municipal, para justificar la disminución de los subsidios, gira en torno a la difícil situación financiera del ente territorial. En el caso concreto, a juicio de la Corte, no consigue satisfacer la carga argumentativa que corresponde a la autoridad municipal, por diversas razones. En primer lugar, porque la supuesta crisis financiera es anterior a la fecha del inicio del proyecto de vivienda de interés social. No se trata por lo tanto de un hecho sobreviviente que pusiera en riesgo la implementación de la política pública en particular, sino de una situación presente desde el momento mismo en que se inició su ejecución, el cual necesariamente debió ser tenido en cuenta por la Administración Municipal.

En segundo lugar la amenaza de crisis financiera del proyecto solo revela errores en la planeación y ejecución presupuestal a cargo del Municipio, razón que tampoco es considerada como una justificación válida para adoptar una medida regresiva, en materia del derecho a la vivienda digna. Los beneficiarios del subsidio no están obligados a soportar la imprevisión y poca eficiencia de las autoridades municipales en la 
ejecución de las políticas públicas, destinadas a la satisfacción de derechos económicos, sociales y culturales. Aceptar un argumento de esta naturaleza iría en contra de los principios que rigen el ejercicio de la función administrativa, y en definitiva, conduciría a privar de contenido a la prohibición de regresión.

Por lo anterior, se ordena a la entidad estatal accionada el cumplimiento de las obligaciones inicialmente pactadas, para la adquisición de unidad de vivienda mínima de interés social correspondiente a la Etapa II de la Urbanización El Sembrador.

\subsection{EI derecho a la vivienda digna en su faceta de defensa frente a injerencias arbitrarias}

En la sentencia T 1318 de 2005, la Corte, por medio de una nota al pie, recoge las sentencias T 308 de 1993 y T 309 de 1995, en las cuales establece la faceta de defensa del derecho a la vivienda digna, frente a injerencias arbitrarias.

Se caracterizan y distinguen de los casos anteriores, en que aquí los accionantes son propietarios de viviendas y las autoridades públicas por medio de una acción u omisión impiden el goce del derecho a la vivienda digna.

En la sentencia T 309 de 1995 se establece como problema jurídico determinar si se viola el derecho fundamental a la vivienda digna, cuando la administración municipal después de demoler una vivienda de propiedad del accionante, como parte de un programa de adecuación de las mismas, frente a personas en una condición manifiesta de debilidad económica, detiene la construcción de la vivienda de remplazo por la falta de suscripción del acta de iniciación de los trabajos por parte del contratista.

En el caso expuesto, para la Corte la conducta de la administración repercute en el daño o la amenaza a derechos fundamentales y por tanto cabe la acción de tutela para su protección, en cuanto las violaciones que la hacen aplicable no solamente consisten en conductas positivas de quien ejerce poder sino en omisiones, es decir, en la inactividad del ente público, pues al abstenerse injustificadamente de llevar a cabo los actos que de ella se esperan, en particular girar los recursos económicos para que el constructor continúe la obra, establecen un actuar negligente, que pone en riesgo prerrogativas básicas de personas en concreto. 
Así las cosas, la mora en la ejecución de unas obras que en sí mismas no revisten ninguna complejidad, ni representan erogaciones cuantiosas implica sin dudarlo, una omisión de la administración municipal en el cumplimiento de sus deberes constitucionales.

La Corte concede la tutela impetrada, ordenando al Alcalde Municipal que adopte las medidas necesarias para reconstruir la vivienda, ya que las señaladas imprecisiones en nada modifican el hecho cierto, de que le ha causado y se le sigue causando perjuicio.

Por último, en la sentencia T 308 de 1993 la Corte estudia si se vulnera el derecho a la vivienda digna de los habitantes de una zona de urbanización, en la cual está ubicado un batallón, por cuanto los militares realizan entrenamientos con armas de fuego, en el día y en altas horas de la noche, a una distancia de 22 metros de los inmuebles, exponiendo a los residentes del sector, a estar en la línea de tiro de los soldados, ya que no existe un muro de seguridad, ni acústica para amortiguar el ruido, ni las balas.

Para la Corte Constitucional, los accionantes estaban frente a "la imposición de una carga consistente en soportar el ruido permanente de las prácticas de tiro, que perturbaba notablemente la tranquilidad de las personas que habitaban la urbanización vecina". De igual forma, una vez las condiciones jurídico-materiales se encuentran cumplidas, de manera que la persona ha entrado a gozar de un derecho de esta categoría, el derecho constitucional materializado adquiere fuerza normativa directa y a su contenido esencial deberá extenderse la necesaria protección constitucional.

De acuerdo con lo anterior, la esencia del derecho a la vivienda es la función que cumple como condición de posibilidad para una vida plena. Esta condición hace parte del núcleo esencial del derecho a una vivienda digna, por lo que su desconocimiento, al socavar la tranquilidad del hogar, constituye una violación de un derecho constitucional cuya efectividad está materialmente garantizada.

En este caso, en especial, la Corte confirma la sentencia de primera instancia, que ordena al Comandante del Batallón de Infantería tomar las medidas necesarias para evitar el ruido producido por las prácticas reiteradas de tiro (colocación de silenciadores, acústica, resonancia, etc.) o, de no ser posible, clausurar en el término de tres meses el polígono del Batallón. 


\section{CONCLUSIONES}

Se presentan a continuación los resultados de los capítulos anteriores, que reportan la evolución del derecho a la vivienda digna desde el punto de vista jurisprudencial. De acuerdo con lo anterior, se expuso el cambio en la concepción del derecho social a la vivienda digna, desde dos facetas: una de defensa y otra de prestación, en las cuales la Corte Constitucional colombiana, a través de la jurisprudencia de tutela, planteó que a pesar de la ya conocida naturaleza prestacional de un derecho eminentemente social, existen dos modalidades en las cuales este derecho adquiere la estructura de derecho subjetivo.

Esta tesis encuentra su fundamento en la introducción de teorías vanguardistas y comprometidas con la eficacia de los derechos sociales al ordenamiento jurídico colombiano, así como en tratados internacionales ratificados por el Estado colombiano, los cuales están originados en principios, siendo el más importante el de la dignidad humana que es comprendido íntegramente.

La principal consecuencia de esta concepción, es que se abrió el espectro de protección judicial del derecho a la vivienda digna mediante el uso directo de la acción de tutela en las dos facetas relatadas, superando la tesis primigenia que restringía su amparo al hecho de tener que demostrar una vulneración del mismo en conexidad con otro derecho considerado, sin debates, como fundamental, o por la afectación del mínimo vital, si el demandante se encontraba en situación de debilidad manifiesta.

Desde este punto de vista resultó imprescindible examinar el derecho a la vivienda digna en la faceta de defensa frente a injerencias arbitrarias, y la prestacional de prohibición del retroceso de una obligación estatal definida, para reconocer la naturaleza del mismo en su connotación externa (estructura subjetiva) e interna (núcleo esencial), como derecho fundamental a partir de las sentencias de tutela que traten sobre el tema, expuestas por la Corte Constitucional de Colombia.

Ahora bien, respecto del análisis del derecho a la vivienda digna en la faceta de defensa frente a injerencias arbitrarias por parte del Estado, es peculiar que en las primeras sentencias, T 308 de 1993 y T 309 de 1995, la Corte no haya tenido conciencia de que los argumentos que aportaba para evitar la vulneración de este derecho social cuando estaba de por medio una injerencia estatal, correspondían a una nueva línea de pensamiento doctrinal, y años después, con la sentencia T 1318 de 2005, 
en la cual reconoció de manera taxativa que en decisiones pasadas había fallado protegiendo la faceta de defensa del derecho ya referido.

Si bien la Corte no propuso una definición para fijar con claridad la naturaleza del derecho a la vivienda digna en la faceta de defensa, este escrito trata de superar ese vacío, y la construye a partir de lo que en verdad llama la atención, que es el concepto de injerencia arbitraria. Con ayuda de las sentencias analizadas, se hace hincapié en que esta abarca tanto acciones (contaminación auditiva por los disparos provenientes de un batallón), como omisiones (no ejecución de las obras de construcción a casas que amenazaban con desplomarse) por parte del Estado, sobre particulares propietarios de una vivienda, que han adquirido esa condición, antes de que comenzara la injerencia arbitraria (sentencia T 309 de 1995) o la ostentan durante la misma (sentencia T 308 de 1993), de tal manera que obstaculizan el disfrute pacífico de la misma. La orden que emitió la Corte Constitucional, consistió en tomar las medidas necesarias para evitar el ruido producido por los disparos, y la reconstrucción de la vivienda.

Respecto del derecho a la vivienda digna, en la faceta prestacional de prohibición del retroceso de una obligación estatal definida, a pesar de que hubo un mayor desarrollo argumentativo por parte de la Corte Constitucional, no se encontró una definición propia para explicar su naturaleza, la cual, se procedió a determinar, a partir del concepto de política pública definida.

Se encontró, dos situaciones en las que se consolidó una política pública definida. Los casos expuestos en las sentencias T 761 de 2011, y T 1318 de 2005, estaban relacionados con la concesión y desembolso de subsidios de vivienda, para poder acceder a un programa de vivienda de interés social promovido por una entidad estatal, del cual, los accionantes ya habían cumplido con todos los requisitos establecidos por la ley para el efecto, pero no pudieron obtener su vivienda, debido a una medida regresiva tomada por parte de una entidad estatal que en concreto evitó el desembolso del subsidio o bajó el monto que inicialmente se había prometido del mismo. Por otro lado, en la sentencia T 585 de 2008, la política pública se definió en el hecho de haber garantizado la inclusión al programa de reasentamiento de viviendas, a familias que habitaban en una zona catalogada como de alto riesgo. De acuerdo con lo anterior, la medida regresiva consistió en excluir a la familia del accionante del programa de reasentamiento. En síntesis, en todos los casos expuestos, la Corte Constitucional resolvió prohibir esas medidas 
regresivas, y cumplir con la obligación prometida, concediendo el desembolso del subsidio en la forma pactada inicialmente, así como ordenar el reasentamiento de la familia que habita en una zona declarada como de alto riesgo.

En conclusión, se aplaude en primer lugar a la Corte Constitucional por desarrollar nuevas garantías de protección que ayudan a lograr una mayor definición de la naturaleza jurídica del derecho a la vivienda digna, superando la indeterminación del artículo 51 constitucional, al aportar nuevos ingredientes al núcleo esencial del derecho, que si bien siempre han partido del respeto por la dignidad humana, ahora están íntimamente relacionados con el respeto por las obligaciones estatales de no interrumpir el disfrute pacífico de una vivienda (faceta de defensa), y a su vez, garantizar el cumplimiento de todos los compromisos suscritos y definidos sobre un titular para que pueda acceder a una vivienda digna (faceta prestacional).

Por lo tanto, ya no se podrá rechazar por improcedente en ningún momento una acción de tutela que busque la protección del derecho a la vivienda digna en la faceta de defensa frente a injerencias arbitrarias y la prestacional de prohibición del retroceso de una obligación estatal definida, sino que deberá buscarse sus momentos de justiciabilidad, inclusive como derecho subjetivo.

\section{BIBLIOGRAFÍA}

Abramovich, V., \& Courtis, C. (2000). Los derechos sociales como derechos exigibles. Madrid: Trotta.

Alexy, R. (1993). Teoría de los derechos fundamentales. Madrid: Centro de Estudios Constitucionales.

Arango, R. (2012). Panorama de derecho comparado. Colombia. En G. Escobar Roca, Derechos sociales y tutela antidiscriminatoria. España: Thomson Reuters Arazandi.

Asamblea General de las Naciones Unidas. (1966). Recuperado el 28 de Abril de 2014, de http://www2.ohchr.org/spanish/law/cescr.htm

Bernal Pulido, C. (2008). El derecho de los derechos. Escritos sobre la aplicación de los derechos fundamentales. Bogotá: Universidad Externado de Colombia. 
Colombia - Constitución Política de Colombia.

Colombia - Corte Constitucional de Colombia. Sentencia T 308 de 1993

(M. P. Eduardo Cifuentes Muñoz: Agosto 4 de 1993).

Colombia - Corte Constitucional de Colombia. Sentencia T 309 de 1995 (M. P. Jose Gregorio Hernández Galindo: Julio 13 de 1995).

Colombia - Corte Constitucional de Colombia. Sentencia T 958 de 2001 (M. P. Eduardo Montealegre Lynett: Septiembre 6 de 2001).

Colombia - Corte Constitucional de Colombia. Sentencia T 1318 de 2005 (M. P. Humberto Antonio Sierra Porto: Diciembre 14 de 2005).

Colombia - Corte Constitucional de Colombia. Sentencia T 585 de 2008 (M. P. Humberto Antonio Sierra Porto: Junio 12 de 2008).

Colombia - Corte Constitucional de Colombia. Sentencia T 760 de 2008 (M. P. Manuel José Cepeda Espinosa: Julio 31 de 2008).

Colombia - Corte Constitucional de Colombia. Sentencia T 235 de 2011 (M. P. Luis Ernesto Vargas Silva: Marzo 31 de 2011).

Comité de Derechos Económicos Sociales y Culturales. (1991). Recuperado el 06 de Abril de 2014, de http://www.escrnet.org/docs/i/428687

Escobar Roca, G., \& González González, B. (2012). El derecho a la vivienda. En G. Escobar Roca, Derechos sociales y tutela antidiscriminatoria. España: Thomson Reuters Arazandi.

Ferrajoli, L. (2004). Derechos y garantías: La ley del más débil. Madrid: Trotta.

Gómez Serrano, L. (2008). Teorías de los derechos fundamentales. Bogotá: Ediciones Doctrina y Ley LTDA.

López Medina, D. (2000). El derecho de los jueces. Bogotá: Legis.

Pisarello, G. (2007). Los derechos sociales y sus garantías. Madrid: Trotta. 
Pisarello, G., \& Observatorio DESC. (2003). Vivienda para todos: Un derecho en (de) construcción. Barcelona: Icaria. 